\title{
DESIGN OF STAIR-CLIMBING WHEELCHAIR USING TRI-WHEEL
}

\section{MECHANISM}

\section{POTHAMSETTY KASI V RAO}

Assistant Professor, Department of Mechanical Engineering, Koneru Lakshmaiah Education Foundation,

Vaddeswaram, Guntur, Andhra Pradesh, India

\begin{abstract}
The objective of this work is to develop a mechanism for climbing up and down over stairs for physically disabled people. The mechanism involved is a tri-wheel mechanism for climbing up and down stairs. The modeling is done in SolidWorks designing software and analysis is carried out in ANSYS software. Tri-wheel mechanism is a unique mechanism for climbing stairs. The analysis is carried out by considering three different materials and the best material is suggested for fabrication. The mechanism involved is a tri-wheel mechanism which is unique and simple in design for climbing stairs. The shaft is designed based on theoretical force analysis and the wheelchair is designed. The design of components is done using SolidWorks software and analysis is done using ANSYS software. Stress, strain, and deformation analysis are done by considering three different materials and best material is suggested. The tri-wheel mechanism is simple for fabrication and it reduces the total cost of fabrication of wheelchair. These results will help to design of shaft based on human weight. With the help of tri-wheel mechanism stair-climbing wheelchair, we can move easily up and down on stairs without building ramps in hospitals, by this construction area and money can be reduced for building hospitals.

KEYWORDS: Stretcher, Stairs, Tri-Wheel Mechanism, Wheel Chair, Ramp \& ANSYS
\end{abstract}

Received: May 10, 2018; Accepted: May 30, 2018; Published: Jul 26, 2018; Paper Id.: IJMPERDAUG201875

\section{INTRODUCTION}

Day to day the patients with disabilities go on increasing, nearly $15 \%$ of the world population are disabled according to "the globally disabled report". The physically disabled people have less living space and the life is seriously affected and faces difficulty problems with their family. Stair-climbing wheelchair plays an important role in the life of disabled people. The society nowadays concentrating on physical disabled and old people developing and constructing elevators, but it is not possible everywhere we go. The disabled people feel difficult to travel from one place to another due to inconvenient for them by using an ordinary wheelchair even though they have help from others. So most of the times the physically disabled people will remain in homes due to lack of facilities like elevators and uneven roads. Due to the above activities, it may influence their physiology and psychology.

This work is mainly based on disadvantages of existing stair-climbing wheelchair and how to overcome this design based on our tri-wheel mechanism. The tri-wheel mechanism is optimized and added to a wheelchair. The tri-wheel mechanism also prevents the wheelchair to climb easily up and down stairs and also to move freely in bump holes, etc. It improves the security and comfort of the wheelchair. All the parts of the wheelchair are modeled using Solid Works designing software and analyzed in ANSYS software. 


\section{DESIGN AND MODELING}

\section{Tri-Wheel Mechanism}

The tri-wheel function will be same as like an ordinary wheel on the flat ground when an external force acts on the lever it climbs stairs due to the rolling action of wheels.

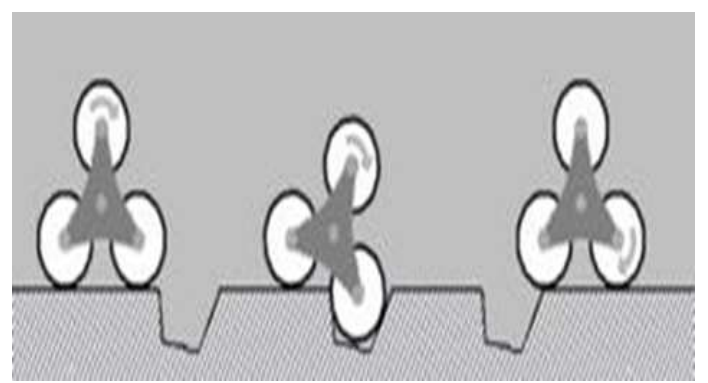

Figure 1: Tri-Wheel Working Mechanism

This wheel design is so simple, it consists of three wheels, each wheel is mounted on a separate shaft and the shafts are mounted the almost like vertices of the equilateral triangle. When these wheels are arranged in quasi-planetary fashion, these set of wheels can negotiate different types of surfaces like surface with sand and mud. This mechanism allows traveling over obstructions like rocks, holes, bumps, and stairs. Of the three wheels moving forward two wheels be in rolling action and the third wheel remains idle. When an obstruction occurs, the lower front wheel will stop moving forward, but the driving axle remains in motion and the top wheel will now come into action as a new front wheel. The top wheel usually lands on top of obstruction and rest of assembly will move over the obstruction. The same process repeats until the required destination is reached.

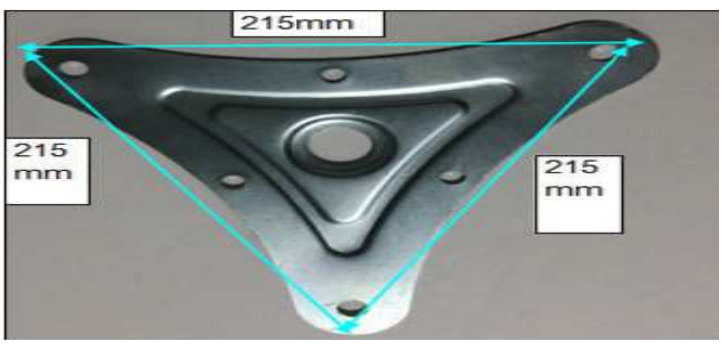

Figure 2: Quasi Planetary Wheel Frame

In this work, we are replacing the tri-wheel assembly in place of normal wheels for stair climber to move up and down comfortable and easily over obstacles like bumps, holes, and stair on the way.

\section{Wheel Frame}

The wheel frame is designed to hold the tri-wheels comfortable on each side of the shaft. The wheel frame, first it is made of straight wheel frame and became more complicated while climbing so it is modified to quasi-planetary wheel frame to create more frictional force and provide smooth power transmission for climbing stairs. This quasi-planetary wheel frame is suitable to transmit exact velocity ratio. The wheel frame setup is designed to provide higher efficiency. The maintenance is less because of simple design parts and failure occurs in the bolt, washer, nuts, etc. 


\section{Force Analysis}

Force analysis deals with what are the different types of forces acting on the components or system. It is done mainly to determine the dimensions of the components. The various parameters involved are the weight of the human body, weight of wheelchair, the force applied on lever, reaction force.

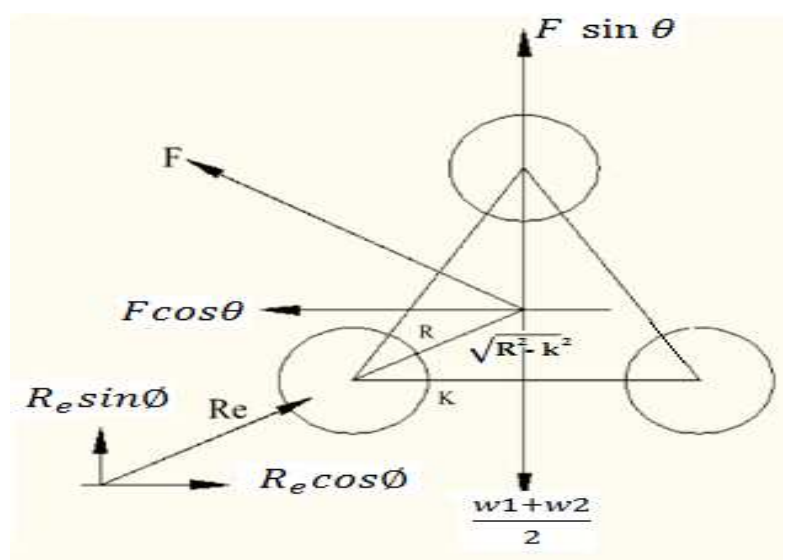

Figure 3: Force Analysis of Wheel

Where,

$\mathrm{W} 1=$ weight of the human body to be carried

W2= weight of the wheelchair

$\mathrm{R}_{\mathrm{e}}=$ reaction force on one side

$\mathrm{F}=$ force applied (on one lever)

$\mathrm{R}=18 \mathrm{~cm}$

$\mathrm{k}=14.5 \mathrm{~cm}$

Applying equilibrium conditions:

Equilibrium condition on moments:

$\left(\frac{w 1+w 2}{2}-F \sin \theta\right) \cdot k=F \cos \theta \cdot \sqrt{R^{2}-k^{2}}$

Equilibrium condition of forces on the X-axis:

$R_{e} \cos \emptyset=F \cos \theta$

Equilibrium condition of forces on the y-axis:

$R_{e} \sin \emptyset+F \sin \theta=\frac{w 1+W 2}{2}$ 


\section{Maximum Load Calculations}

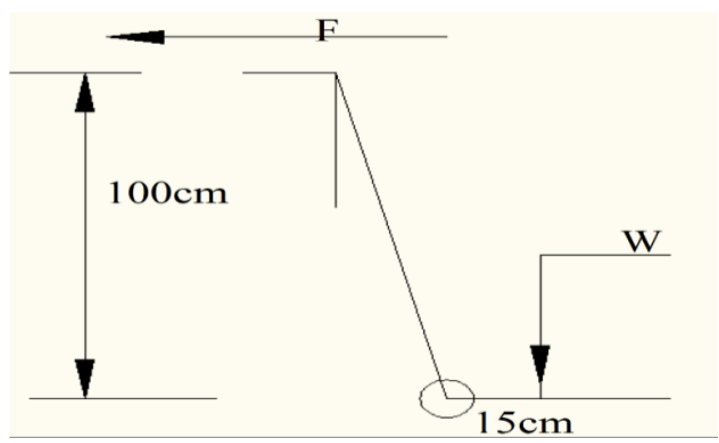

Figure 4: Maximum Load Calculations

$\mathrm{F} \times 100=\mathrm{W} \times 15$

$\mathrm{W}=(100 / 15) \times \mathrm{F}$

When we assume $\mathrm{F}$ to be $98 \mathrm{~N}$, we get $\mathrm{W}=653.5 \mathrm{~N}$

Where $\mathrm{F}=$ Force applied on the lever, $\mathrm{W}=$ weight of the object measured in Newton.

\section{Bending Moment and Stress Analysis}

When an external force or moment acting on an element causing the element to bend, the bending moment is the reaction force induced in the component. It is done to know the maximum moment or force where the element can sustain. The parameters involved are different types of forces acting on it. The horizontal bending moment is calculated based on horizontal bending moment analysis diagram, a vertical bending moment is calculated based on vertical bending moment analysis diagram and the resultant bending moment is calculated considering both horizontal and vertical bending moment diagram. The shaft diameter is calculated by initializing parameters (not accurate) like the weight of the human body, a weight of wheelchair, lever force and resultant bending moment.

Let the length of the shaft $=1 \mathrm{~m}$

Span of forces $=\mathrm{a}($ distance between $\mathrm{A}$ and B $)$

\section{Horizontal Bending Moment Analysis}

The horizontal bending moment diagram represents the horizontal forces acting on the shaft.

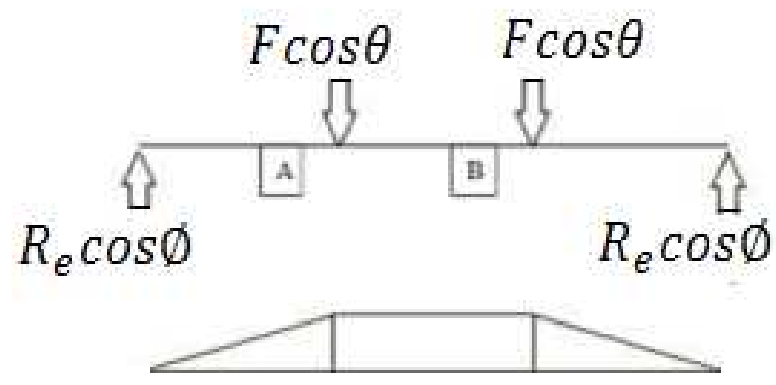

Figure 5: Horizontal Load and Bending Moment

Bending Moment at point A: 


$$
\text { B. } M \text { at } A=R_{e} \cos \emptyset \cdot x(1 / 2-a / 2) \text { Clock Wise }
$$

Bending Moment at point B:

$$
\text { B. } M \text { at } B=R_{e} \cos \emptyset \cdot x(1 / 2-a / 2) \text { Counter Clock Wise }
$$

\section{Vertical Bending Moment Analysis}

The vertical bending moment diagram represents the vertical forces acting on the shaft.

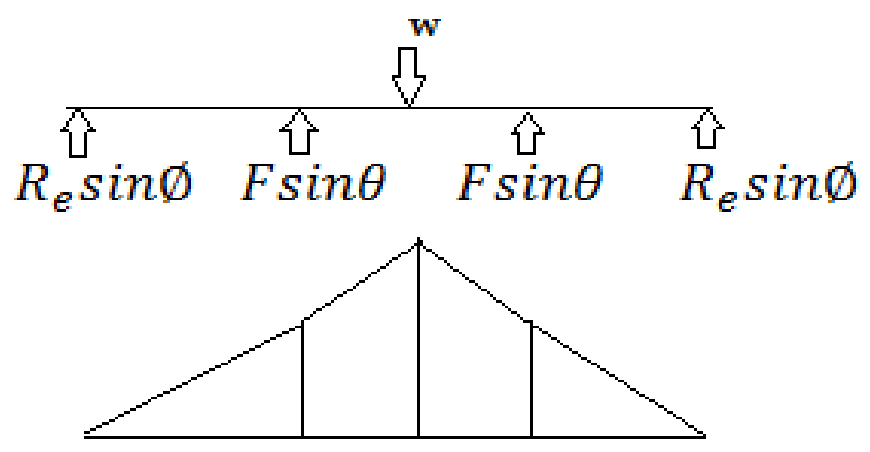

Figure 6: Vertical Load and Bending Moment

The critical section is identified to be the middle section

Maximum Moment at point B:

$\left(\mathrm{M}_{\mathrm{b}}\right)_{\max }=\mathrm{R}_{\mathrm{e}} \sin \varphi .(\mathrm{L} / 2)+\mathrm{F} \sin \theta .(\mathrm{A} / 2)$

$\sigma_{\max }=\left(\mathrm{M}_{\mathrm{b}}\right)_{\max } / \mathrm{Z}$

Where, $d=$ diameter of shaft

If, $\mathrm{W}_{1}=67 \mathrm{~kg}, \mathrm{~W}_{2}=20 \mathrm{~kg}, \mathrm{a}=33 \mathrm{~cm}, \mathrm{l}=38 \mathrm{~cm}, \theta=45^{\circ}, \mathrm{n}=60$ and $\mathrm{R}_{\mathrm{e}}=75 \mathrm{~N}$

Therefore, by the above analysis and estimates following moment is obtained as

$\left(\mathrm{M}_{\mathrm{b}}\right)_{\max }=6550 \mathrm{~N} \mathrm{~mm}$

By Solving we get shaft diameter as $\mathrm{d}=25.4 \mathrm{~mm}$

\section{MODELING OF STAIR CLIMBER WHEELCHAIR COMPONENTS}

Stair climbing components like wheelchair frame, seat, armpad of the arm, gripper, caster fork, tri-wheels, footrest and backrest are designed using Solid works modeling tool. 


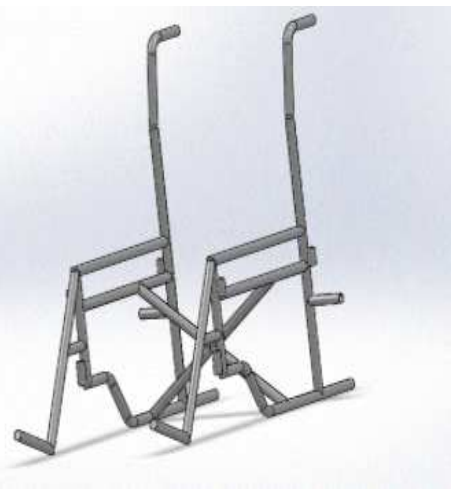

(a)

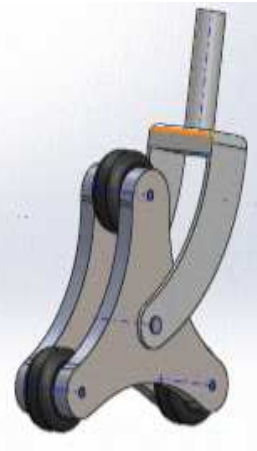

(b)

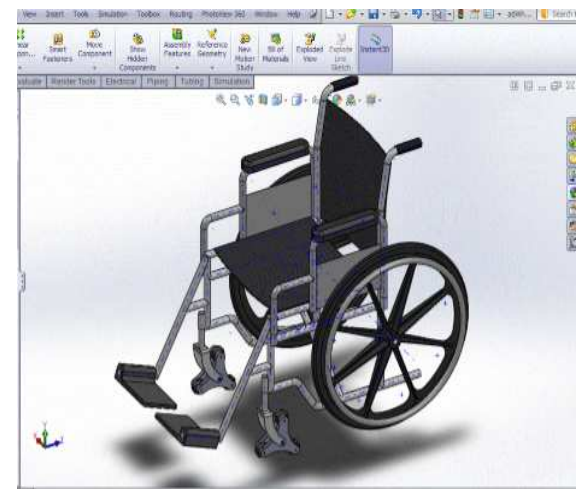

(c)

Figure 7: Modeling Parts of Wheelchair:
(a) Wheel Chair Frame
(b) Assembly of Tri-wheel with Caster Fork
(c) Assembly of Wheel Chair

\section{FABRICATION OF WHEEL CHAIR}

The following processes were used in the fabrication of wheelchair:

- Gas cutting: Gas cutting uses oxygen and fuel gases to cut the different lengths of hollow mild steel pipes as per required design. The parameters to be considered are the temperature of gases for steel pipes.

- Pipe bending: Human powered-tube bending process is employed to bend two mild steel hollow pipes at an angle $60^{0}$ for pipe handle.

- Plasma arc cutting: Plasma arc cutting is used for cutting four tri-wheel webs made up of stainless steel by means of an accelerated jet of hot plasma.

- Arc welding: Arc-Welding is used to join trolley parts together which create an electric arc between electrode and base material by using a welding power supply to melt the metals at the welding point.

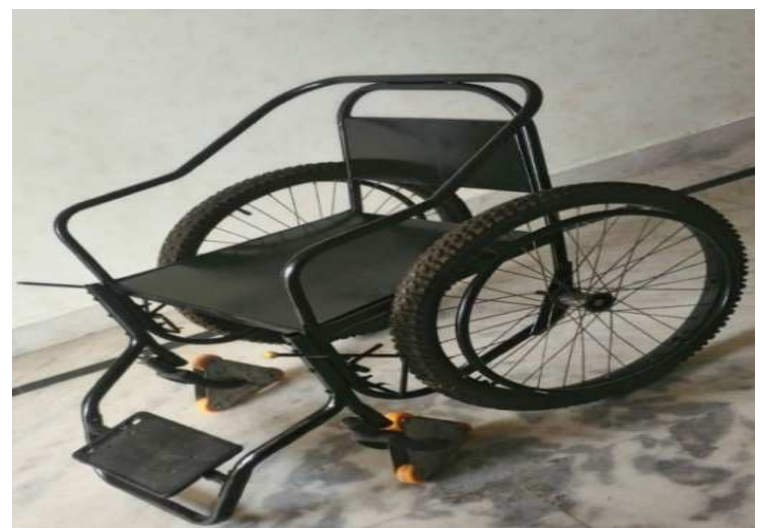

Figure 8: Fabricated Wheel Chair using Tri-Wheel Mechanism

\section{RESULTS AND DISCUSSIONS}

Quasi-planetary wheel frame is selected to create more frictional force and provide smooth power transmission for climbing stairs out of different wheel frames like straight wheel frame, curved wheel frame etc. The theoretical calculation is done for calculating the shaft diameter by considering different parameters. The model is modeled in Solid Works 
designing tool and analyzed in ANSYS software based on factors like human weight, lever force applied on the lever and material properties.

Table 1: Comparison of Stress, Strain, and Deformation for Different Material

\begin{tabular}{|l|c|c|c|}
\hline \multicolumn{1}{|c|}{ Material } & $\begin{array}{c}\text { Max Stress } \\
(\mathbf{P a})\end{array}$ & Max Strain & $\begin{array}{c}\text { Max Deformation } \\
(\mathbf{m})\end{array}$ \\
\hline Structural steel & $5.5039 \times 10^{7}$ & 0.00028 & $1.7483 \times 10^{-6}$ \\
\hline Aluminum alloy & $6.0547 \times 10^{7}$ & 0.00102 & $5.0106 \times 10^{-6}$ \\
\hline Stainless steel & $5.3623 \times 10^{7}$ & 0.00028 & $1.5508 \times 10^{-6}$ \\
\hline
\end{tabular}

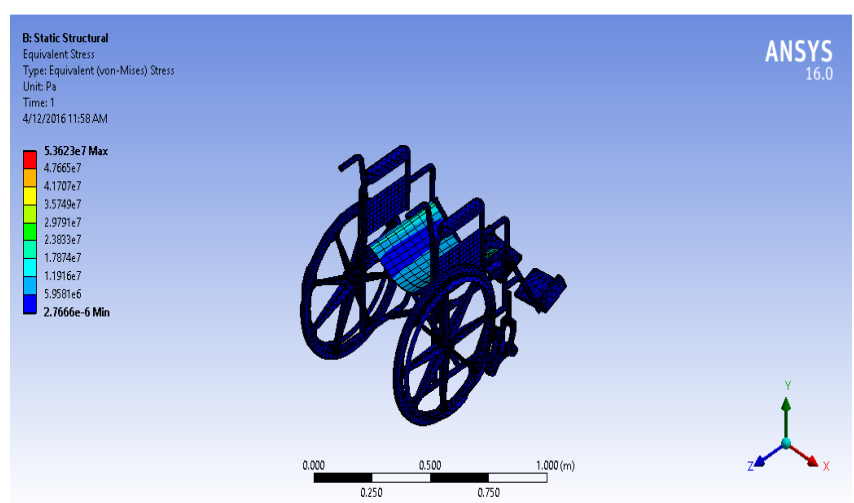

Figure 9: Stress Analysis Results of Wheel

Chair Made of Stainless Steel

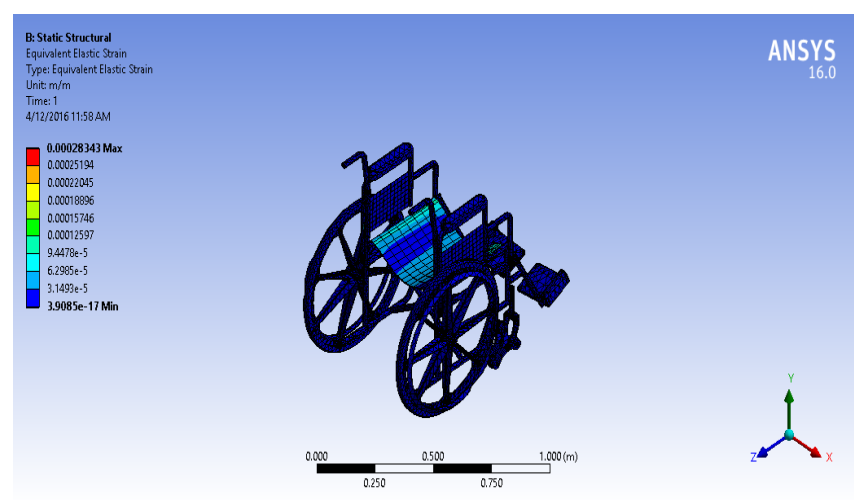

Figure 10: Strain Analysis Results of Wheelchair Made of Stainless Steel

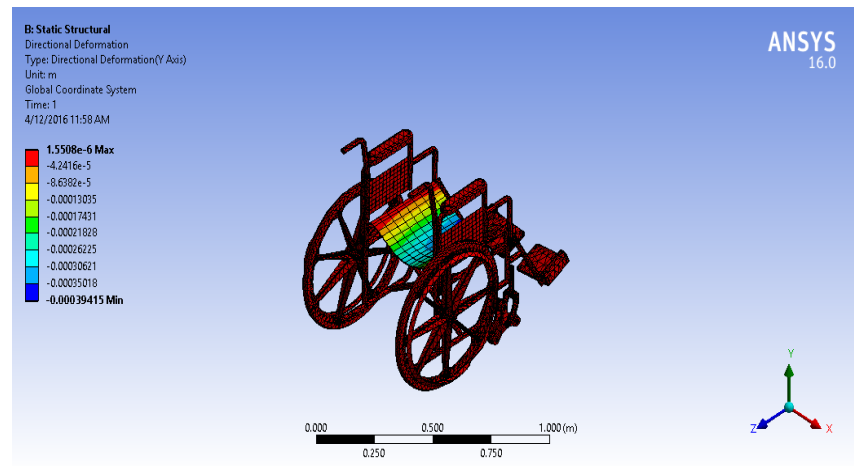

Figure 11: Deformation Results of Wheel Chair Made of Stainless Steel 


\section{CONCLUSIONS}

The stair-climbing wheelchair is designed with the help of the tri-wheel mechanism which has a compact structure and can cope with the flat or inclined terrain, stairs, and obstacles. The quasi-planetary wheel frame is selected as a triwheel frame to create more frictional force and provide smooth power transmission for climbing stairs. The theoretical calculation is done for calculating the shaft diameter by considering different parameters. Parts of wheelchair were modeled in software Solid Works and analyzed in software ANSYS.

- The shaft is designed based on loads assuming and the dimensions are calculated.

- The optimization of design has been designed to make the wheelchair more convenient and comfortable.

- Assembling simulation is carried out in Solid Works in order to avoid interference between different parts of the wheelchair.

- Analyzed by considering different material properties and suggest the best material (Stainless steel) for manufacturing.

\section{REFERENCES}

1. Prof. Girish Sudhir Modak and Prof. Dr. Manmohan M. Bhoomkar, "Innovative design of staircase climbing wheelchair", International Journal of Engineering Research \& Technology (IJERT), vol. 2 issue 2, February 2013

2. Chakradeo SN, Abraham RM, Rani BA, Manjula R. Data mining: Building a social network. Indian Journal of Science and Technology. 2015 Jan; 8(S2):212-6.

3. Ekachai Chaichanasiri and Teerapol Puangumpan, "A prototype of a stair-climbing system for a wheelchair”, The Second TSME International Conference on Mechanical Engineering, 19-21 October 2011.

4. Lawn, M. J., Sakai, T., Kuroiwa, M. and Ishimatsu, T. (2001). Development and practical application of a stair climbing wheelchair in Nagasaki, International Journal of Human-friendly Welfare Robotics Systems, vol.2(2), pp. 33-39.

5. K. Narendra Kumar, A. Gopichand, M. Gopala Anjaneyulu and B. Gopi Krishna, "Design and development of adjustable stair climbing robot”, International Journal of Research in Engineering and Technology (IJRET), vol. 02 issue: 04 | Apr-2013.

6. Murray J. Lawn and Takakazu Ishimatsu, "Modeling of a stair climbing wheelchair mechanism with high single-step capability”, IEEE Transactions on Neural Systems and Rehabilitation Engineering, vol. 11, no. 3, September 2003

7. Bhavsar H, Ganatra A. A comparative study of training algorithms for supervised machine learning. IJSCE. 2012 Sep; 2(4). ISSN: 2231-2307.

8. R Rajasekar, "Design and fabrication of staircase climbing wheelchair", International Journal of Mechanical Engineering and Robotics Research (IJMERR), vol. 2, no. 2, April 2013.

9. Ekachai Chaichanasiri and Teerapol Puangumpan, "A prototype of a stair-climbing system for a wheelchair", The Second TSME International Conference on Mechanical Engineering, 19-21 October 2011.

10. Padghan, K. K., AK Pitale, JP Modak, and AP Narkhedkar. "Design and Analysis Of Cad Based Human Powered Flywheel Motor By Using Quick Return Ratio One Mechanism."

11. G. Quaglia, W. Franco and M. Nisi, "Evolution of stair-climbing wheelchair", 14th IFTOMM World Congress, Taipei, Taiwan, October 25-30, 2015 
12. Lawn, M. J., Sakai, T., Kuroiwa, M. and Ishimatsu, T. (2001). Development and practical application of a stair climbing wheelchair in Nagasaki, International Journal of Human-friendly Welfare Robotics Systems, vol.2(2), pp. 33-39.

13. P. Wellman, W. Krovi, V. Kuma, W. Harwin, "Design of a Wheelchair with Legs for People with Motor Disabilities," in IEEE Trans. Rehab. Eng., vol. 3, pp. 343-353, 1995

14. Wellman, P., Krovi, V., Kumar, V. and Harwin, W. (1995). Design of a wheelchair with legs for people with motor disabilities, IEEE Transactions on Rehabilitation Engineering, vol.3 (4), pp. 343-353

15. Deepika P, Thenmozhi K. A heart disease prediction using classification with different decision tree techniques. International Journal of Engineering Research and General Science. 2014 Oct/Nov; 2(6):6-11.

16. D. R. Voves, J. F. Prendergast, and T. J. Green, "Stairway chairlift mechanism," U. S. Pat. 4913 264, Apr. 1990

17. K. Narendra Kumar, A. Gopichand, M. Gopala Anjaneyulu and B. Gopi Krishna, "Design and development of adjustable stair climbing robot”, International Journal of Research in Engineering and Technology (IJRET), vol. 02 issue: 04 | Apr-2013. 
